\title{
Catecholaminergic depletion in nucleus accumbens enhances trace conditioning
}

\author{
Nelson $\mathrm{AJD}^{1}$, Thur $\mathrm{KE}^{1}$, Spicer $\mathrm{C}^{2}$, Marsden $\mathrm{CA}^{2}$, Cassaday $\mathrm{HJ}^{1^{*}}$ \\ 1 Institute of Neuroscience, Schools of Psychology, University of Nottingham, Nottingham, UK \\ 2 Biomedical Sciences, University of Nottingham, Nottingham, UK
}

* CORRESPONDING AUTHOR:

Institute of Neuroscience, School of Psychology

University of Nottingham

University Park, Nottingham

NG7 2RD, UK

Tel: + 44 (0) 115951 5124; Fax: +44 (0) 1159515324

email: helen.cassaday@nottingham.ac.uk (Helen Cassaday)

\author{
Received 28.09.2010 \\ Accepted 10.03.2011 \\ Advances in Medical Sciences \\ Vol. 56(1) - 2011 - pp 71-79 \\ DOI: $10.2478 / \mathrm{v} 10039-011-0014-2$ \\ (C) Medical University of Bialystok, Poland
}

\begin{abstract}
Purpose: To examine the effect of dopamine depletion in nucleus accumbens on trace conditioning; to distinguish the role of core and shell sub-regions, as far as possible. Material/Methods: 6-hydroxydopamine was used to lesion dopamine terminals within the core and shell accumbens. Experiment 1 assessed conditioning to a tone conditioned stimulus that had previously been paired with footshock (unconditioned stimulus) at a 30s trace interval. Experiment 2 subsequently assessed contiguous conditioning (at 0 s trace) using a light conditioned stimulus directly followed by the unconditioned stimulus.

Results: Both sham and shell-lesioned animals showed the normal trace effect of reduced conditioning to the trace conditioned stimulus but 6-hydroxydopamine injections targeted on the core subregion of the nucleus accumbens abolished this effect and enhanced conditioning to the trace conditioned stimulus. However, the depletion produced by this lesion placement extended to the shell. In Experiment 2 (at 0s trace), there was no effect of either lesion placement as all animals showed comparable levels of conditioning to the light conditioned stimulus. Neurochemical analysis across core, shell and comparison regions showed some effects on noradrenalin as well as dopamine.

Conclusions: The pattern of changes in noradrenalin did not systematically relate to the observed behavioural changes after core injections. The pattern of changes in dopamine suggested that depletion in core mediated the increased conditioning to the trace conditioned stimulus seen in the present study. However, the comparison depletion restricted to the shell subregion was less substantial, and a role for secondarily affected brain regions cannot be excluded.
\end{abstract}

Key words: conditioned emotional response; associative learning; 6-hydroxydopamine

\section{INTRODUCTION}

In conditioned emotional response (CER) procedures, systemic amphetamines increased fear conditioning to a stimulus that was of low salience for associative learning because of the introduction of a trace interval between the conditioned stimulus (CS) and unconditioned stimulus (UCS) outcome $[1,2]$. The amphetamines are indirect catecholamine agonists, so, in terms of underlying substrates, these results suggest a role for dopamine (DA) or noradrenalin (NA). Moreover, there is rapidly mounting evidence, from a range of test procedures, consistent with a key role for DA in the modulation of a variety of associative learning processes [3-5], including fear conditioning [6-11].
Although the picture is complex, effects of dopaminergic modulation within NAc are most consistently demonstrated in fear conditioning procedures where the predictiveness or salience of cues is experimentally reduced [12-18] or reversed in extinction [10,11] see [19] for review. Similarly, noradrenergic signalling has been implicated in the extinction of classically conditioned responses [20-22]. However, in a trace fear conditioning procedure mice deficient in the NA transporter (and thus with increased circulating catecholamines) showed - contrary to our behavioural data [1,2] - reduced conditioning as measured by autonomic responses [23].

With respect to underlying brain structures which modulate trace conditioning, the role of DA transmission within the nucleus accumbens (NAc) has previously been examined using excitotoxic [24] and electrolytic lesions [25], neither of which 
reproduce the pattern of effects seen under amphetamines in CER procedures, i.e. increased conditioning to the trace CS measured behaviourally as conditioned suppression. However, although electrolytic and excitotoxic lesions offer a relatively good method to distinguish the shell and core sub-regions, they are not selective to catecholaminergic neurones.

Therefore, in the present study, we used the catecholaminergic neurotoxin 6-hydroxydopamine (6-OHDA) injected at different coordinates within NAc to produce differential depletions within core and shell subregions. The effects of these depletions were examined using two tests of discrete cue conditioning. In Experiment 1, we assessed conditioning to a tone CS that had previously been paired with footshock UCS at a 30 s trace interval. Contiguous conditioning (at 0 s trace) was run as a comparison test in Experiment 2, which examined conditioning to a light CS paired contiguously (0s) with the UCS. Thus the objective of the present study is to compare the earlier-reported increase in trace but not delay conditioning produced by treatment with amphetamines [1,2] with the effects of a regionally specific intervention that shows neurochemical selectivity. Based on the evidence reviewed above, we predict a role for NAc where the predictiveness of the CS is experimentally reduced, i.e. in trace but not delay conditioning.

The amphetamines which earlier increased trace conditioning are indirect agonists, increasing the availability of DA and NA at all the available receptor subtypes. The 6-OHDA lesions used in the present study reduce the availability of DA and NA and on this basis would be expected to have opposite rather than similar effects to treatment with amphetamines. However, under some circumstances, dopaminergic lesions reproduce the effects of DA agonists, specifically for behaviours modulated by DA D2-like receptors, because the effects of agonists at DA D2-like receptor subtypes are inhibitory rather than excitatory [19,26,27]. In this event, we would predict that 6-OHDA induced depletion in core should be the critical lesion placement to enhance conditioning over the trace interval, based on the effects of neurochemically non-selective NAc lesions in trace conditioning procedures $[23,24]$.

The 6-OHDA depletions were verified by high-pressure liquid chromatography (HPLC) with electrochemical detection. Tissue was sampled using established micro-punch methods $[17,18,28]$. In addition to samples taken from shell and core, the prelimbic and infralimbic cortex were selected on the basis of their known interconnectivity with NAc [29-31]. The striatum was selected to assess whether there had been any significant spread of neurotoxin dorsal from the injection site.

\section{MATERIAL AND METHODS}

\section{Subjects}

Twenty four naïve male Wistar rats (Charles River, UK) were caged in pairs on a 12:12 h light/dark cycle, given free access to food and water, handled for approximately $10 \mathrm{~min}$ per day for 1 week prior to any procedure, then at mean weight $271 \mathrm{~g}$ (range 255-310g) underwent surgery. Eight rats were randomly allocated to each of the core and shell injection groups and a total of 8 rats were allocated to the 'sham' condition (4 were vehicle-injected at core and 4 were vehicle-injected at the shell coordinates).

All procedures were carried out in accordance with the United Kingdom Animals Scientific Procedures Act 1986, Project Licence number PPL 40/2648.

\section{Surgery}

These methods have been described in detail elsewhere $[17,18,28]$. All animals were pre-treated with parglyine (Sigma, UK) (50mg/kg) and desipramine (Sigma, UK) (20mg/ $\mathrm{kg}$ ) subcutaneously (s.c.) 40 min prior to surgery. Anaesthesia was induced by isoflurane (Abbot, UK) $(4 \%)$ in a $\mathrm{N}_{2} \mathrm{O} / \mathrm{O}_{2}$ $(1: 2, \mathrm{v} / \mathrm{v})$ mixture and maintained thereafter with isoflurane $(1-2 \%)$. Animals were placed in a stereotaxic frame with the incisor bar set at $-3.3 \mathrm{~mm}$ below the intra-aural line. A craniotomy was performed with a $1 \mathrm{~mm}$ hand drill (to make a hole of approximate diameter $1 \mathrm{~mm}$ ) and the dura was cut to expose the cortex. Rats received bilateral infusions of 6-OHDA hydrobromide or vehicle into either NAc core or medial shell at the following stereotaxic coordinates: core at $\mathrm{AP}+1.6 \mathrm{~mm}, \mathrm{ML} \pm 1.8 \mathrm{~mm}$, DV $-6.8 \mathrm{~mm}$; medial shell at AP $+1.3 \mathrm{~mm}, \mathrm{ML} \pm 1.0 \mathrm{~mm}, \mathrm{DV}-6.2 \mathrm{~mm}$ [32]. DV coordinates were taken from dura. Infusions were made via a 31 gauge stainless steel injector attached by polythene tubing to a $1 \mu 1$ Hamilton syringe. At each coordinate site, $0.5 \mu 1$ of either vehicle $(0.9 \%$ saline/ascorbic acid $0.01 \% \mathrm{w} / \mathrm{v}$ ) or vehicle and 6-OHDA $(24 \mathrm{mg} / \mathrm{ml}$ as salt; Sigma, UK) was infused over $2 \mathrm{~min}$. The injectors were left in situ for $5 \mathrm{~min}$. Rimadyl (Pfizer, UK) $(0.03 \mathrm{ml}$, s.c. $)$ provided post-operative analgesia.

\section{Behavioural Apparatus}

Six identical fully automated conditioning chambers, housed within sound-attenuating cases containing ventilation fans (Cambridge Cognition, Cambridge, UK), were used. Each of the inner conditioning chambers consisted of a plain steel box $(25 \mathrm{~cm} \times 25 \mathrm{~cm} \times 22 \mathrm{~cm}$ high $)$ with a Plexiglas door $(27 \mathrm{~cm} \mathrm{x}$ $21 \mathrm{~cm}$ high) at the front. The floor was a shock grid with steel bars $1 \mathrm{~cm}$ apart and $1 \mathrm{~cm}$ above the lip of a $7 \mathrm{~cm}$ deep sawdust tray. Mounted in one wall were three stimulus lights and a waterspout.

The spout was $5 \mathrm{~cm}$ above the floor and connected to a lickometer supplied by a pump. Licks were registered by the breaking of the photo beam within the spout, which also triggered water delivery of $0.05 \mathrm{ml}$ per lick. The waterspout 
was illuminated when water was available. A loudspeaker for the presentation of auditory stimuli was set in the roof. Two stimuli were used in this experiment. A $5 \mathrm{~s}$ mixed frequency noise set at $85 \mathrm{~dB}$ (including background) served as the target $\mathrm{CS}$ in the trace condition. A $5 \mathrm{~s}$ flashing light, provided by the three wall mounted stimulus lights and the house light flashing both on $(0.5 \mathrm{~s})$ and off $(0.5 \mathrm{~s})$ for the $5 \mathrm{~s}$ duration acted as the CS in the contiguous condition. Footshock of $1 \mathrm{~s}$ duration and $1 \mathrm{~mA}$ intensity was delivered through the grid floor by a constant current shock generator (pulsed voltage: output square wave $10 \mathrm{~ms}$ on, $80 \mathrm{~ms}$ off, $370 \mathrm{~V}$ peak under no load conditions, MISAC Systems, Newbury, UK). Stimulus control and data collection was by an Acorn Archimedes RISC computer programmed in Basic with additional interfacing using an Arachnid extension (Cambridge Cognition).

\section{Behavioural Procedure}

After a minimum 1-week recovery period during which the rats were handled for $5 \mathrm{~min}$ daily, rats were water deprived, receiving $1 \mathrm{~h}$ of free access to water per day (food was available ad libitum in the home cage). After pre-conditioning in which the rats learnt to lick in the boxes, the same animals underwent two tests of discrete cue conditioning. In Experiment 1, rats were conditioned to a noise CS at a 30s trace interval and then underwent an off-the-baseline test of conditioning to the trace CS. Subsequently, in Experiment 2, the animals were conditioned to a second CS (light) at a 0 s trace interval and the level of conditioning to the light CS was measured using the same test procedure. Both experiments were conducted during the light phase.

\section{Pre-conditioning}

Rats were shaped for 1 day until all drank from the waterspout and individually assigned to a conditioning box for the duration of the experiment. There then followed 5 days of preconditioning, in which rats drank in the experimental chamber for 15 min each day (timed from first lick). The drinking spout was illuminated throughout, but there were no other stimuli presented in this phase. Latency to first lick was measured as an indicator of habituation to the experimental context. Total number of licks was also recorded each day to assess any preexisting differences in drinking (prior to conditioning).

\section{Experiment 1}

30s trace conditioning: Conditioning was conducted in 1 day following the last pre-conditioning day. No water was available within the chamber and the waterspout was not illuminated. There were 2 trace conditioning trials in which the UCS footshock was delivered with a 30s trace interval following termination of the $5 \mathrm{~s}$ noise CS. The first pairing of CS and UCS was presented after $5 \mathrm{~min}$ had elapsed, and the second pairing was at $5 \mathrm{~min}$ after the first, with a further $5 \mathrm{~min}$ left in the apparatus following the second shock presentation. In the absence of drinking, there were no behavioural measures to record.
Reshaping: On the day following conditioning, animals were reshaped following the same procedure as in preconditioning sessions. This was in order to re-establish drinking after conditioning. Reshaping also provided measures of conditioning to the box context (latency to first lick; number of licks made in the first two minutes).

Noise test (30s trace CS): On the day following reshape, the animals were placed in the experimental chambers and conditioned suppression to the noise CS was tested. Water was available throughout the test and the waterspout was illuminated. Once the animals had made 50 licks, the noise $\mathrm{CS}$ was presented in an off-the-baseline test (of up to $15 \mathrm{~min}$ total duration). The latency to make 50 licks in the absence of the CS (the A period) provided a measure of any individual variation in baseline lick responding and was compared with the time taken to complete 50 licks following $\mathrm{CS}$ onset (B period) in a suppression ratio $(\mathrm{A} /(\mathrm{A}+\mathrm{B}))$ to assess the level of conditioning to the noise $\mathrm{CS}$ (though completion of the $\mathrm{B}$ period did not terminate exposure to the CS). Differences in the level of conditioning to the tone were also measured as the number of licks made in the first two minutes of the test following stimulus onset.

\section{Experiment 2}

Os trace conditioning: On the next day, the animals underwent a second conditioning session that was conducted in exactly the same manner as above, albeit the flashing light served as the $5 \mathrm{~s} \mathrm{CS}$ and the footshock was presented immediately after the offset of the light CS, i.e. without a trace interval (0s).

Reshaping: On the next day the animals were reshaped for 15 min to re-establish drinking, as described above.

Light test ( 0 s trace CS): The level of conditioning to the contiguously conditioned CS was assessed in exactly the same manner as to the trace CS, except that once the animals had completed 50 licks the light CS was presented.

\section{Neurotransmitter Assay}

These methods have been described in detail elsewhere $[17,18,28]$. Following the completion of behavioural testing, the animals were humanely killed by dislocation of the neck and then decapitated. The brains were removed rapidly and dissected on a cold tray. A $2 \mathrm{~mm}$ coronal slice of brain containing the ventral and dorsal striatum and a separate $2 \mathrm{~mm}$ slice containing the medial prefrontal cortex was made using a chilled brain matrix (Harvard Instruments, USA). The brain samples were then immediately frozen on dry ice and stored at $-80^{\circ} \mathrm{C}$. Subsequently, a $0.84 \mathrm{~mm}$ diameter stainless steel micropunch was used to remove samples of tissue from the following (left and right) brain regions: core NAc, medial shell NAc, prelimbic cortex and infralimbic cortex. A $1.6 \mathrm{~mm}$ diameter stainless steel micropunch was used to remove sample tissue from the dorsolateral striatum. Tissue punch samples were stored in $1.5 \mathrm{ml}$ Eppendorf tubes and frozen at $-80^{\circ} \mathrm{C}$. 
Table 1A. Absolute levels of dopamine and noradrenalin (pmoles/ $\mu$ g protein; +S.E.M.) in tissue samples from core NAc, shell NAc, dorsolateral striatum (DLS), prelimbic (PL) and infralimbic cortices (IL) to show changes produced by sham, core and shell 6-OHDA injections.

\begin{tabular}{|c|c|c|c|c|c|c|}
\hline & $\begin{array}{l}\text { Dopamine } \\
\text { (pmoles/ } \mu \mathrm{g})\end{array}$ & & & $\begin{array}{l}\text { Noradrenalin } \\
(\mathrm{pmoles} / \mu \mathrm{g})\end{array}$ & & \\
\hline Region & Sham & Core Injection & Shell Injection & Sham & Core Injection & Shell Injection \\
\hline $\begin{array}{l}\text { Core } \\
\text { Sample }\end{array}$ & $\begin{array}{l}5.879 \\
( \pm 0.739)\end{array}$ & $\begin{array}{l}2.212 \\
( \pm 0.374)\end{array}$ & $\begin{array}{l}5.633 \\
( \pm 1.189)\end{array}$ & $\begin{array}{l}1.098 \\
( \pm 0.354)\end{array}$ & $\begin{array}{l}0.422 \\
( \pm 0.222)\end{array}$ & $\begin{array}{l}0.196 \\
( \pm 0.085)\end{array}$ \\
\hline $\begin{array}{l}\text { Shell } \\
\text { Sample }\end{array}$ & $\begin{array}{l}4.72 \\
( \pm 0.782)\end{array}$ & $\begin{array}{l}2.102 \\
( \pm 0.417)\end{array}$ & $\begin{array}{l}2.707 \\
( \pm 0.576)\end{array}$ & $\begin{array}{l}1.529 \\
( \pm 0.288)\end{array}$ & $\begin{array}{l}0.787 \\
( \pm 0.38)\end{array}$ & $\begin{array}{l}0.129 \\
( \pm 0.016)\end{array}$ \\
\hline $\begin{array}{l}\text { DLS } \\
\text { Sample }\end{array}$ & $\begin{array}{l}9.176 \\
( \pm 0.089)\end{array}$ & $\begin{array}{l}6.348 \\
( \pm 1.626)\end{array}$ & $\begin{array}{l}7.386 \\
( \pm 0.811)\end{array}$ & $\begin{array}{l}0.068 \\
( \pm 0.011)\end{array}$ & $\begin{array}{l}0.043 \\
( \pm 0.017)\end{array}$ & $\begin{array}{l}0.042 \\
( \pm 0.008)\end{array}$ \\
\hline $\begin{array}{l}\text { PL } \\
\text { Sample }\end{array}$ & $\begin{array}{l}0.0324 \\
( \pm 0.001)\end{array}$ & $\begin{array}{l}0.0301 \\
( \pm 0.017)\end{array}$ & $\begin{array}{l}0.0176 \\
( \pm 0.007)\end{array}$ & $\begin{array}{l}0.128 \\
( \pm 0.008)\end{array}$ & $\begin{array}{l}0.099 \\
( \pm 0.006)\end{array}$ & $\begin{array}{l}0.068 \\
( \pm 0.016)\end{array}$ \\
\hline $\begin{array}{l}\text { IL } \\
\text { Sample }\end{array}$ & $\begin{array}{l}0.0492 \\
( \pm 0.012)\end{array}$ & $\begin{array}{l}0.036 \\
( \pm 0.01)\end{array}$ & $\begin{array}{l}0.022 \\
( \pm 0.005)\end{array}$ & $\begin{array}{l}0.284 \\
( \pm 0.084)\end{array}$ & $\begin{array}{l}0.339 \\
( \pm 0.147)\end{array}$ & $\begin{array}{l}0.184 \\
( \pm 0.04)\end{array}$ \\
\hline
\end{tabular}

Table $1 B$. Percentage difference in DA and NA levels (+S.E.M.) to show changes produced by 6-OHDA at core and shell injection coordinates compared to vehicle-injected sham-lesioned animals in the 5 brain regions assayed. Planned comparisons: * $\mathbf{p}<0.05$, ** p $<0.01$, by t-test.

\begin{tabular}{lllll}
\hline & \multicolumn{2}{l}{ Dopamine\% difference } & \multicolumn{2}{l}{ Noradrenalin \% difference } \\
\hline Region & Core & Shell & Core & Shell \\
& Injection & Injection & Injection & Injection \\
\hline Core & $-62.4^{* *}$ & -4.12 & -61.6 & $-82.1 *$ \\
Sample & \pm 6.4 & \pm 20.2 & \pm 20.2 & \pm 7.7 \\
\hline Shell & $-55.0^{*}$ & $-42.65 *$ & $-48.5^{*}$ & $-91.6 * *$ \\
Sample & \pm 8.88 & \pm 12.2 & \pm 24.8 & \pm 1.0 \\
\hline DLS & -30.8 & -19.5 & -36.2 & -38.3 \\
Sample & \pm 17.7 & \pm 8.8 & \pm .24 .4 & +12.2 \\
\hline PL & -7.0 & -41.2 & -23.6 & $-48.5 * *$ \\
Sample & \pm 47.1 & \pm 21.9 & \pm 5.1 & \pm 12.6 \\
\hline IL & -26.8 & $-55.7 *$ & +19.4 & -35.2 \\
Sample & \pm 21.0 & \pm 9.4 & \pm 51.9 & \pm 15.8 \\
\hline
\end{tabular}

Neurotransmitter levels in the samples were determined by HPLC with electrochemical detection. The tissue samples were homogenised in $0.1 \mathrm{M}$ PCA solution by sonication and centrifuged at $17400 \mathrm{~g}$ for $20 \mathrm{~min}$ at $4^{\circ} \mathrm{C}$. The supernatant was injected onto the HPLC system in $4-8 \mu 1$ volumes. Neurotransmitter levels were detected using a glassy carbon electrode flow cell (VT-03 Antec) with an ISAAC reference electrode.

Results were analysed using Alexys software data system. Bradford assay was used to adjust for protein content.

\section{Design and Analysis}

Planned comparisons by t-test were used to assess the selectivity of the lesion. Weight changes were analysed over the first 7 post-operative days, by the same between-subjects factor of lesion, in a repeated measures analysis of variance (ANOVA). All behavioural analyses were by ANOVA with alpha set at $\mathrm{p}<0.05$ for the rejection of the null hypothesis. Where necessary, raw latency data (time to first lick at pre- training and reshape) were log transformed so that their distribution was suitable for parametric analysis. In both experiments, there was a single between-subjects factor of lesion (vehicle, core, shell). Significant main effects of lesion were further explored by t-test.

\section{RESULTS}

\section{Neurotransmitter Assay}

Quantification of the selectivity of the lesions by HPLC revealed no evidence of DA depletion in 3 of the 8 core injected animals and consequently these animals were not considered for either behavioural or further neurochemical analysis. Tab. $1 A$ displays the absolute levels (pmoles/ $\mu \mathrm{g}$ protein) of DA and NA in the 5 brain regions from which samples were taken. Tab. $1 B$ shows the same data as the percentage depletion.

As is clear from Tab. $1 B$, infusion of 6-OHDA into the core NAc produced a statistically significant reduction in DA levels compared to vehicle infused controls in the core NAc $(>60 \%)$ but also in the medial shell NAc (55\%). These lesions are therefore presented as core $(+$ shell) in all subsequent analyses and discussion. The shell injection, on the other hand, led to DA depletion that was selective to the medial shell NAc. A significant depletion in DA was also found in the infralimbic cortex following the shell NAc lesion. Similarly, significant changes in NA were not restricted to the site of injection.

\section{Post-operative weight changes}

All the rats' weights increased over the 7 days of post-operative recovery. There was a main effect of days $\left(\mathrm{F}_{(6,108)}=96.94\right.$, $\mathrm{p}<0.01)$. There was a marginal days by lesion interaction consistent with some fluctuation in the recovery rate by lesion condition $\left(\mathrm{F}_{(12,108)}=1.77, \mathrm{p}=0.06\right)$. However, there was no overall effect of lesion $(\mathrm{F}<1)$ and - by day 7 - weights in the different lesion conditions were very similar (mean weights: sham $=303 \mathrm{~g}$; core $(+$ shell $)=294 \mathrm{~g}$; shell $=297 \mathrm{~g})$. 
Table 2. Mean latencies $(\log 10) s( \pm$ S.E.M.) to first lick in the reshape session following conditioning to the trace 30 s $C S$ (Experiment 1$)$ and trace 0s CS (Experiment 2) for the sham-, core(+shell)- and shell- lesioned groups.

\begin{tabular}{llll}
\hline & Sham & $\begin{array}{l}\text { Core }(+ \text { shell }) \\
\text { Lesion }\end{array}$ & $\begin{array}{l}\text { Shell } \\
\text { Lesion }\end{array}$ \\
\hline Expt 1: 30s Trace & $1.09( \pm 0.26)$ & $1.73( \pm 0.27)$ & $1.22( \pm 0.14)$ \\
\hline Expt 2: 0s Trace & $1.29( \pm 0.32)$ & $1.16( \pm 0.44)$ & $1.72( \pm 0.34)$ \\
\hline
\end{tabular}

Figure 1. Mean suppression ( \pm S.E.M.) to a tone CS that had previously been paired with footshock at a $30 \mathrm{~s}$ trace interval, for the sham - (white bars), core(+shell) - (grey bars) and shell (black bars) 6-OHDA lesions.

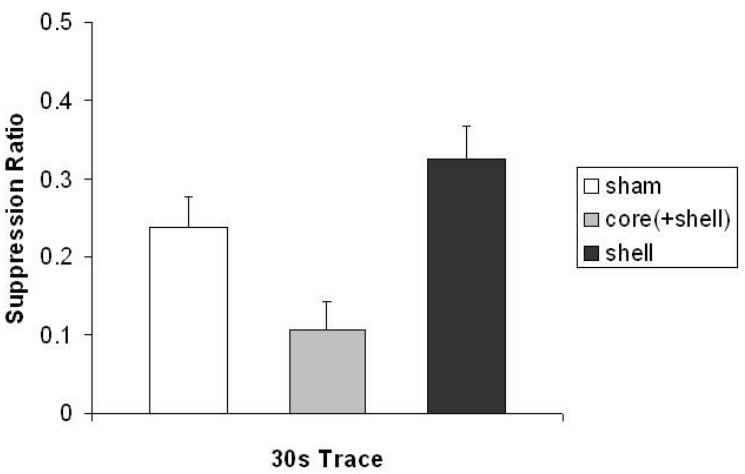

\section{Behavioural}

\section{Pre-conditioning}

There were no baseline differences prior to conditioning as there was no effect of lesion on total amount drunk or latency to lick over the 5 days of lick training $\left(\max \mathrm{F}_{(2,18)}=1.14\right.$, $\mathrm{p}=0.34)$.

\section{Experiment 1}

Reshaping: There was no evidence that the level of conditioned fear elicited by the experimental chamber measured in the reshape sessions following conditioning (drink latency data presented in Tab. 2) differed by lesion $\left(\mathrm{F}_{(2,18)}=1.64, \mathrm{p}=0.22\right)$. Analysis of the number of licks during the first two minutes of the reshape session confirmed this conclusion $(\mathrm{F}<1)$.

30 s Trace Test: Analysis of the A periods showed no difference in the latency to make 50 licks in the absence of the $\mathrm{CS}$ by lesion condition $(\mathrm{F}<1)$. Figure 1 displays the mean suppression ratios to the 30 s trace CS (noise) by lesion. The level of suppression to the 30 s trace CS differed by lesion with the core (+shell) group showing the most and the shell group the least conditioned suppression to the trace CS. This description of the data was confirmed statistically by ANOVA which yielded an effect of lesion $\left(\mathrm{F}_{(2,18)}=5.99, \mathrm{p}=0.01\right)$. Subsequent analysis with t-tests confirmed that the core $(+$ shell $)$ group showed greater conditioning to the trace CS compared to both the sham- $\left(\mathrm{t}_{(11)}=2.26, \mathrm{p}<0.05\right)$ and shell-operated animals $\left(\mathrm{t}_{(11)}=3.49, \mathrm{p}<0.005\right)$ but there was no difference between the sham- and shell-operated animals $\left(\mathrm{t}_{(14)}=1.47, \mathrm{p}=0.16\right)$. This differential level of conditioning seen to the 30s trace CS was also revealed by examination of lick behaviour in the first two minutes of the test following stimulus onset as there was
Figure 2. Mean suppression ( \pm S.E.M.) to a light CS that had previously been paired with footshock at a 0 s trace interval, for the sham - (white bars), core(+shell) - (grey bars) and shell - (black bars) 6-OHDA lesions.

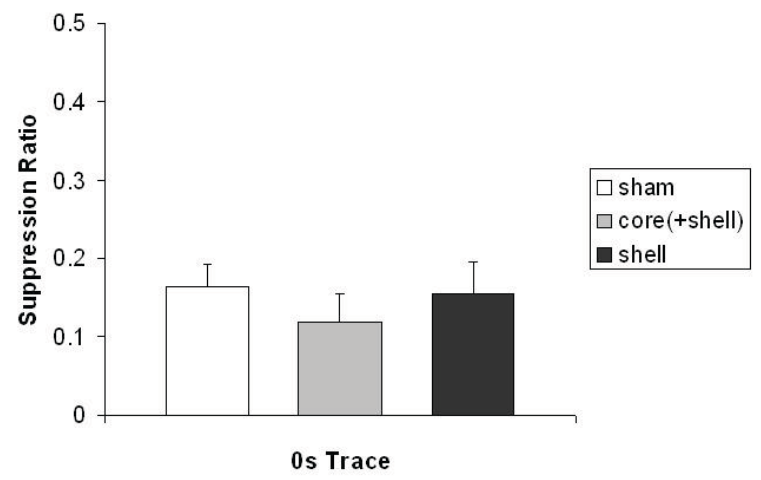

an effect of lesion $\left(\mathrm{F}_{(2,18)}=4.09, \mathrm{p}<0.05\right)$. This effect arose because the core $(+$ shell) group drank less than the shell group $\left(\mathrm{t}_{(14)}=3.31, \mathrm{p}<0.05\right)$ with mean licks per $\min \left({ }_{+}\right.$S.E.M $)$: sham $=148.8( \pm 31.7)$; core $(+$ shell $)=75.6( \pm 34.6)$; shell $=199.8$ $( \pm 20.5)$.

\section{Experiment 2}

Reshaping: The groups did not differ in terms of latency to first lick in the reshape session following conditioning to the $0 \mathrm{~s}$ trace (Tab. 2). Statistically, there was no effect of lesion $(\mathrm{F}<1)$ Similarly, there was no effect of lesion on the amount drunk during the first two minutes of the reshape session $(\mathrm{F}<1)$.

Test: Analysis of the A periods showed no difference in the latency to make 50 licks in the absence of the CS by lesion condition $(\mathrm{F}<1)$. Moreover, comparison of the A periods between Experiments 1 and 2 showed no significant differences, either overall or in relation to lesion, all $\mathrm{Fs}_{\mathrm{s}}<1$. Thus there was no evidence that the latency to make 50 licks in the absence of the CS was increased by context-induced fear. The mean suppression ratios to the 0s trace CS (light) for the different injection coordinates within NAc are presented in Figure 2. Lesion was without effect on the level of conditioning seen to the contiguously-conditioned light $\mathrm{F}<1$. Similarly, there was no effect on the number of licks in the 2 min following stimulus onset $(\mathrm{F}<1)$ 


\section{DISCUSSION}

Figure 1 shows that both sham- and shell-lesioned animals showed the normal trace effect of weak conditioning to the trace CS. By contrast 6-OHDA injection targeted on the core subregion of the NAc enhanced conditioning to the trace CS such that the level of conditioning in the core(+shell) group was increased compared to both sham- and shell-lesioned animals. Conversely, when conditioned without a trace in Experiment 2, there was no effect of injection with 6-OHDA at either set of coordinates as all animals showed comparable levels of conditioning to the light CS.

There is noideal comparison group against which to evaluate trace conditioning without some potentially confounded lesion effect on delay conditioning and/or timing. For example, the relative length of the CS and trace has recently been shown to be a key determinant of sensitivity to hippocampal lesions [33]. Thus, rather than using a conventional control group, repeat conditioning has been used to evaluate the effects of hippocampal lesions in trace conditioning [34]. To prevent generalization between CSs, Experiment 2 used a different modality of stimulus (flashing light rather than mixed frequency noise). This raises the possibility that the lack of any lesion effect in Experiment 2 was down to the modality of the stimulus rather than the absence of a trace interval. However, in similar fear conditioning procedures, conditioning to various noise and flashing light stimuli has been demonstrated to be equivalently affected after a variety of dopaminergic drug [1,2] and lesion treatments [14,35-37]. Similarly, conditioned DA release within NAc has been found to be increased irrespective of whether a tone or flashing light is paired with footshock [8]. Alternatively, increased contextual conditioning in consequence of the repeat conditioning procedure could have masked the emergence of differences by lesion group in the Experiment 2 delay conditioning procedure. Analyses of the reshaping data and the A periods at test showed no evidence to suggest that the level of contextual conditioning was affected by lesion or increased from Experiment 1 to Experiment 2. However, repeating the experiments in the reverse order and with counterbalanced noise/light stimulus identities would be needed to eliminate these possibilities entirely.

The existing literature on the role of the catecholamines in the acquisition versus extinction of conditioned fear is mixed and the particular pathway under investigation is clearly a key factor [19]. In the case of NAc, there is compelling evidence from dialysis studies for its role in the acquisition of conditioned fear $[8,38]$. Yet some of the behavioural evidence points to a particular role for NAc DA in the extinction of conditioned fear rather than its acquisition [11,20-21]. Effects of amphetamine and haloperidol within NAc - which are now well-established to be mediated at acquisition - have been demonstrated in more elaborate fear conditioning procedures which manipulate the salience of the CS through pre-exposure in latent inhibition [16-18,39].
However, in agreement with the aforementioned evidence, the acquisition of delay conditioning, run as the control condition to evaluate effects on conditioning to the pre-exposed CS, is typically unaffected by these treatments. For example, in the same CER procedure amphetamine and haloperidol injected in NAc abolished and enhanced latent inhibition respectively. However, these treatments had no significant effect in delay conditioning control groups run with light and noise stimuli $[17,18]$. Similarly, as in the present study, we have found no consistent effects of catecholaminergic depletion in shell or core NAc on delay conditioning $[17,18]$. Thus, although the 6-OHDA lesion method in use does not allow us to distinguish effects on acquisition versus the extinction of conditioned fear, the lack of effect of our 6-OHDA injections in Experiment 2 is consistent with the results of earlier studies, and most importantly with studies from the same laboratory using the same CER procedure [18].

In sum, earlier behavioural studies point to a particular role for NAc DA in conditioned fear paradigms where the salience or predictiveness of cues is manipulated or reversed $[15,19]$, using latent inhibition [14,16-18], blocking [12,13] or extinction procedures [10,11]. The results of Experiment 1 extend these findings by showing the potential equivalence of a trace interval between CS offset and UCS as a method to manipulate the predictiveness of the CS.

In line with other work, the NAc DA depletions produced in the present study were moderate, most likely because of the relatively low concentration of 6-OHDA administered and in a small injection volume to reduce the likelihood of spread to the adjacent subfield $[17,18,28]$. Neurochemically, the effects of 6-OHDA were clearly different according to the injection coordinates. Tab. $1 B$ shows that the shell lesion selectively depleted DA in shell, whilst the 6-OHDA injection targeted on core also produced significant DA depletion in the adjacent shell. The very same pattern of greater susceptibility of the core to DA denervation as well as less neuroanatomical selectivity of the core lesion placement following 6-OHDA infusions into the core or shell has been seen in another study of lesions made by this method [18], as well as independently reported by another group [e.g., 40-42]. The recently described reciprocal intra-accumbal connections, with particularly strong projections from the core to the shell, may underlie the pattern of catecholaminergic denervation that we and others have observed with this kind of lesion [43]. Furthermore, dopaminergic fibres innervating the shell may pass through the anterior commissure which is proximal to the core infusion site used in the current study [44]. Irrespective of the underlying mechanism, the lack of selectivity of the behaviourally effective core lesion could mean that trace conditioning was sensitive to bigger core $(+$ shell) lesions through the 'mass action' of removing more DA from NAc. Nonetheless a role for shell per se would seem to be precluded by the absence of any overall effect on trace conditioning in the shell lesion group. Although not neurochemically selective, the shell lesion was neuranatomically restricted with respect to its primary effects 
on DA (secondary effects are discussed below).

NA protection has been found to be variably effective with lesions of this kind [e.g., 45,46] and desipramine pretreatment was insufficient to protect NA in the present study. In systemic drug studies, the DA agonists that we have found to increase trace conditioning, d-amphetamine and methylphenidate, are indirect and non-specific in that catecholamine uptake and release are increased, thus (irrespective of the origin of the changes) a role for NA in the conditioning processes under test should be considered [23]. The literature can be used to argue against this possibility in that NA afferents to the NAc project primarily to the shell not the core $[47,48]$, yet it was at the core injection site that 6-OHDA enhanced trace conditioning in the present study. Moreover, the injections targeted in core produced no significant changes in NA within the core (indeed the only significant change in NA seen after injection at the core coordinates was in the shell). The fact that shell NA was significantly reduced after injection of 6-OHDA at both placements suggests that changes in shell NA are a poor explanation of the behavioural results. However, the shell lesion was associated with significant DA depletion in frontal cortex (see below) and it is not possible to know whether we would have seen a similar lack of effect on trace conditioning in the absence of this change.

One advantage of the method we used to quantify the 6-OHDA lesion is that it allows the assessment of secondary effects of the lesion in distal but interconnected brain regions that are often overlooked when lesions are verified by conventional histological assessment. In the present study, there were no significant neurochemical changes in dorsolateral striatum and thus no indication that the 6-OHDA injected had diffused dorsally. In line with previous reports [e.g., 49,50], secondary changes in NA and DA levels were observed in the prelimbic and infralimbic cortices, respectively. These reductions in NA and DA were unlikely to be a direct effect of 6-OHDA injection at the coordinates used in the present study and most likely reflect secondary changes in frontal cortex, consistent with the known interconnectivity of these regions with NAc [29,51]. Clearly we would not wish to exclude a role for prefrontal cortex in trace conditioning [52,53]. However, in the present study, changes in frontal cortex were only observed subsequent to injection of 6-OHDA at the shell coordinates (which was without effect on trace conditioning in the present study). Moreover, in other studies, lesions to such interconnected areas (e.g., hippocampal, anterior cingulate) reliably reduced rather than enhanced trace conditioning in aversive procedures, including CER using a 30s trace interval [e.g., 52,54], and this effect is generally viewed as a cognitive impairment. Conversely, enhanced trace conditioning, as demonstrated in the present study, could indicate cognitive enhancement in consequence of improved working memory function [55].

\section{CONCLUSIONS}

We suggest that DA depletion centred on core NAc was the likely mediator of the increased conditioning to the trace CS shown in the present study. As discussed above, the injection of 6-OHDA at the core coordinates also resulted in significant DA depletion in shell. However, 6-OHDA injection in the shell (which produced a DA depletion restricted to shell) was without effect on trace conditioning. NA depletion was seen in both shell and core samples after 6-OHDA injection in the shell. In contrast, the depletion of NA in the core sample after the core injection of 6-OHDA was non significant. Thus, the observed pattern of outcomes suggests that DA (rather than NA) depletion in core (rather than shell) mediated the observed increase in trace conditioning.

The present findings are also consistent with the assumption that the effects of DA agonists on trace conditioning [1,2] are D2-mediated, because they were reproduced by DA depletion $[26,27]$. Follow-up studies with this conditioning procedure should compare the effects of amphetamine and selective D2 receptor agents injected into shell versus core NAc.

\section{ACKNOWLEDGEMENTS}

This work was supported by the Wellcome Trust (ref. 082940). We thank Karen Swift for her invaluable help with the HPLC. The authors declare that they have no competing interests.

\section{REFERENCES}

1. Norman C, Cassaday HJ. Amphetamine increases aversive conditioning to diffuse contextual stimuli and to a discrete trace stimulus when conditioned at higher footshock intensity. J Psychopharmacol. 2003 Mar;17(1): 67-76.

2. Horsley RR, Cassaday HJ. Methylphenidate can reduce selectivity in associative learning in an aversive trace conditioning task. J Psychopharmacol. 2007 Jul;21(5):492-500.

3. Sunsay C, Rebec GV. Real-time dopamine efflux in the nucleus accumbens core during Pavlovian conditioning. Behav Neurosci. 2008 Apr;122(2):358-67.

4. Lex A, Hauber W. Dopamine D1 and D2 receptors in the nucleus accumbens core and shell mediate Pavlovianinstrumental transfer. Learn Memory. 2008 Jul;15(7):483-91.

5. Chaudhri N, Sahuque LL, Schairer WW, Janak PH. Separable roles of the nucleus accumbens core and shell in context- and cue-induced alcohol-seeking. Neuropsychopharmacology. 2010 Feb;35(3):783-91.

6. Martinez RC, Oliveira AR, Macedo CE, Molina VA, Brandao ML. Involvement of dopaminergic mechanisms in the nucleus accumbens core and shell subregions in the expression of fear conditioning. Neurosci Lett. 2008 Dec;446(2-3):112-6.

7. Huertas E, Ponce G, Koeneke MA, Poch C, 
Espana-Serrano L, Palomo T, Jimenez-Arriero MA, Hoenicka J. The D2 dopamine receptor gene variant C957T affects human fear conditioning and aversive priming. Genes Brain Behav. 2010 Feb;9(1):103-9.

8. Young AM, Joseph MH, Gray JA. Latent inhibition of conditioned dopamine release in rat nucleus accumbens. Neuroscience. 1993 May;54(1):5-9.

9. de Oliveria AR, Reimer AE, Brandao ML. Role of dopamine receptors in the ventral tegmental area in conditioned fear. Behav Brain Res. 2009 May;199(2):271-7.

10. Burhans LB, Gabriel M. Contextual modulation of conditioned responses: role of the ventral subiculum and nucleus accumbens. Behav Neurosci. 2007 Dec;121(6):1243-57.

11. Hotzman-Assif $\mathrm{O}$, Laurent $\mathrm{V}$, Westbrook RF. Blockade of dopamine activity in the nucleus accumbens impairs learning extinction of conditioned fear. Learn Memory. 2010 Feb;17(2):71-5.

12. Iordanova MD, Westbrook RF, Killcross AS. Dopamine activity in the nucleus accumbens modulates blocking in fear conditioning. Eur J Neurosci. 2006 Dec;24(11):3265-70.

13. Bradfield LA, McNally GP. The role of nucleus accumbens shell in learning about natural versus excitatory stimuli during Pavlovian fear conditioning. Learn Memory. $2010 \mathrm{Jul} ; 17(7): 337-43$.

14. Weiner I, Gal G, Rawlins JNP, Feldon J. Differential involvement of the shell and core subterritories of the nucleus in latent inhibition and amphetamine-induced activity. Behav Brain Res. 1996 Nov;81(1-2):123-33.

15. Horvitz JC. Mesolimbocortical and nigrostriatal dopamine responses to salient non-reward events. Neuroscience. 2000;96(4):651-6.

16. Weiner I. The "two headed" latent inhibition model of schizophrenia: modelling positive and negative symptoms and their treatment. Psychopharmacology. 2003 Sep;169(3-4):257-97.

17. Nelson AJD, Thur KE, Horsley RR, Spicer C, Marsden CA, Cassaday HJ. Reduced dopamine function within the medial shell of the nucleus accumbens enhances latent inhibition. Pharmacol Biochem Behav. 2011 Mar;98(1):1-7.

18. Nelson AJ, Thur KE, Marsden CA, Cassaday HJ. Dopamine in nucleus accumbens: salience modulation in latent inhibition and overshadowing. J Psychopharmacol. Published online 24 January 2011. http://jop.sagepub.com/content/ early/2011/01/29/0269881110389211. Accessed January 24, 2011.

19. Pezze MA, Feldon J. Mesolimbic pathways in fear conditioning. Prog Neurobiol. 2004 Dec;74(5):301-20.

20. McCormick DA, Thomson RF. Locus coeruleus lesions and resistance to extinction of a classically conditioned response: involvement of the neocortex and hippocampus. Brain Res. 1982 Aug;245(2):239-49.

21. Mueller D, Porter JT, Quirk GJ. Noradrenergic signalling in infralimbic cortex increases cell excitability and strengthens memory for fear extinction. J Neurosci. 2008

\section{Jan;28(2):369-75}

22. Bernardi RE, Lattal KM. A role for $\alpha 1$-adrenergic receptors in extinction of conditioned fear and cocaine conditioned place preference. Behav Neurosci. 2010 Apr;124(2):204-10.

23. Keller NR, Diedrich A, Appalsamy M, Miller LC, Caron MG, McDonald MP, Shelton RC, Blakely RD, Robertson D. Norepinephrine transporter-deficient mice respond to anxiety producing and fearful environments with bradycardia and hypotension. Neuroscience. 2006 Mar;139(3):931-46.

24. Parkinson JA, Robbins TW, Everitt BJ. Selective excitotoxic lesions of the nucleus accumbens core and shell differentially affect aversive Pavlovian conditioning to discrete and contextual cues. Psychobiology. 1999 Jun;27(2):256-66.

25. Cassaday HJ, Horsley RR, Norman C. Electrolytic lesions to nucleus accumbens core and shell have dissociable effects on conditioning to discrete and contextual cues in aversive and appetitive procedures respectively. Behav Brain Res. 2005 May;160(2):222-35.

26. Traynor JR, Neubig RR. Regulators of G protein signaling and drugs of abuse. Mol Interv. 2005 Feb;5(1):30-41.

27. Greengard P. The neurobiology of slow synaptic transmission. Science. 2001 Nov;294(5544):1024-30.

28. Nelson AJD, Thur KE, Marsden CA, Cassaday HJ. Dissociable roles of dopamine within the core and medial shell of the nucleus accumbens in memory for objects and place. Behav Neurosci. 2010 Dec;124(6):789-99.

29. Berendse HW, Galis de Graaf Y, Groenewegen HJ. Topographical organization and relationship with ventral striatal compartments of prefrontal corticostriatal projections in the rat. J Comp Neurol. 1992 Feb;316(3):314-47.

30. Groenewegen HJ, Wright CI, Beijer AV, Voorn P. Convergence and segregation of ventral striatal inputs and outputs. Ann N Y Acad Sci. 1999 Jun 29;877:49-63.

31. Haber SN, Fudge JL, McFarland NR. Striatonigrostriatal pathways in primates form an ascending spiral from the shell to the dorsolateral striatum. J Neurosci. 2000 Mar;20(6):2369-82.

32. Paxinos $\mathrm{G}$, Watson $\mathrm{C}$. The rat brain in stereotaxic coordinates. 3rd ed. San Diego, CA: Academic Press; 1997.

33. Walker AG, Steinmetz JE. Hippocampal lesions in rats differentially affect long- and short-trace eyeblink conditioning. Physiol Behav. 2008 Feb;93(3):570-8.

34. Koh MT, Wheeler DS, Gallagher M. Hippocampal lesions interfere with long-trace taste aversion conditioning. Physiol Behav. 2009 Aug;98(1-4):103-7.

35. Tai C-T, Cassaday HJ, Feldon J, Rawlins JNP. Both electrolytic and excitotoxic lesions of nucleus accumbens disrupt latent inhibition of learning in rats. Neurobiol Learn Mem. 1995 Jul;64(1):36-48.

36. Cassaday HJ, Shilliam CS, Marsden CA. Serotonergic depletion increases conditoned suppression to background stimuli in the rat. J Psychopharmacol. 2001 Jun;15(2):83-92. 
37. Pothuizen HH, Jongen-Rêlo AL, Feldon J, Yee BK. Latent inhibition of conditioned taste aversion is not disrupted, but can be enhanced, by selective nucleus accumbens shell lesions in rat. Neuroscience. 2006 137(4):1119-30.

38. Wilkinson LS, Humby T, Killcross AS, Torres EM, Everitt BJ, Robbins TW. Dissociations in dopamine release in medial prefrontal cortex and ventral striatum during the acquisition and extinction of classical aversive conditioning in the rat. Eur. J. Neurosci. 1998 Mar;10(3):1019-26.

39. Joseph MH, Peters SL, Moran PM, Grigoryan GA, Young AMJ, Gray JA. Modulation of latent inhibition in the rat by altered dopamine transmission in the nucleus accumbens at the time of conditioning. Neuroscience. 2000;101(4):921-30.

40. Boye SM, Grant RJ, Clarke PB. Disruption of dopaminergic neurotransmission in nucleus accumbens core inhibits the locomotor stimulant effects of nicotine and D-amphetamine in rats. Neuropharmacology. 2001 May;40(6):792-805.

41. Sellings LH, Clarke PB. Segregation of amphetamine reward and locomotor stimulation between nucleus accumbens medial shell and core. J Neurosci. 2003 Jul;23(15):6295-303.

42. Sellings LH, Baharnouri G, McQuade LE, Clarke PB. Rewarding and aversive effects of nicotine are segregated within the nucleus accumbens. Eur J Neurosci. 2008 Jul;28(2):342-52.

43. van Dongen YC, Deniau J-M, Pennartz CMA, Galis-de Graaf Y, Voorn P, Thierry AM, Groenewegen HJ. Anatomical evidence for direct connections between the shell and core subregions of the rat nucleus accumbens. Neuroscience. 2005;136(4):1049-71.

44. Sokolowski JD, Salamone JD. The role of accumbens dopamine in lever pressing and response allocation: effects of 6-OHDA injected into core and dorsomedial shell. Pharmacol Biochem Behav. 1998 Mar;59(3):557-66.

45. Sellings LH, Clarke PB. 6-Hydroxydopamine lesions of nucleus accumbens core abolish amphetamine-induced conditioned activity. Synapse. 2006 May;59(6):374-7.

46. Sellings LH, McQuade LE, Clarke PB. Evidence for multiple sites within rat ventral striatum mediating cocaineconditioned place preference and locomotor activation. J Pharmacol Exp Ther. 2006 Jun;317(3):1178-87.
47. Berridge CW, Stratford TL, Foote SL, Kelley AE. Distribution of dopamine beta-hydroxylase-like immunoreactive fibers within the shell subregion of the nucleus accumbens. Synapse. 1997 Nov;27(3):230-41.

48. Delfs JM, Zhu Y, Druhan JP, Aston-Jones GS. Origin of noradrenergic afferents to the shell subregion of the nucleus accumbens: anterograde and retrograde tract-tracing studies in the rat. Brain Res. 1998 Sep;808(2):127-40.

49. Robbins TW, Giardini V, Jones GH, Reading P, Sahakian BJ. Effects of dopamine depletion from the caudateputamen and nucleus accumbens septi on the acquisition and performance of a conditional discrimination task. Behav Brain Res. 1990 May;38(3): 243-61.

50. Parkinson JA, Dalley JW, Cardinal RN, Bamford A, Fehnert B, Lachenal G, Rudarakanchana N, Halkerston KM, Robbins TW, Everitt BJ. Nucleus accumbens dopamine depletion impairs both acquisition and performance of appetitive Pavlovian approach behavior: implications for mesoaccumbens dopamine function. Behav Brain Res. 2002 Dec;137(1-2):149-63.

51. Gorelova N, Yang CR. The course of the neural projection from the prefrontal cortex to the nucleus accumbens in the rat. Neuroscience. 1997 Feb;76(3):689-706.

52. Han CJ, O'Tuathaigh CM, van Trigt L, Quinn JJ, Fanselow MS, Mongeau R, Koch C, Anderson DJ. Trace but not delay fear conditioning requires attention and the anterior cingulate cortex. Proc Natl Acad Sci USA. 2003 Oct;100(22):13087-92.

53. Gilmartin MR, McEchron MD. Single neurons in the medial prefrontal cortex of the rat exhibit tonic and phasic coding during trace fear conditioning. Behav Neurosci. 2005 Feb;119(1):1496-510.

54. McEchron MD, Bouwmeester H, Tseng W, Weiss C, Disterhoft JF. Hippocampectomy disrupts auditory trace fear conditioning and contextual fear conditioning in the rat. Hippocampus. 1998;8(6):638-46.

55. Sweatt JD. Hippocampal function in cognition. Psychopharmacology. 2004 Jun;174(1): 99-110. 